
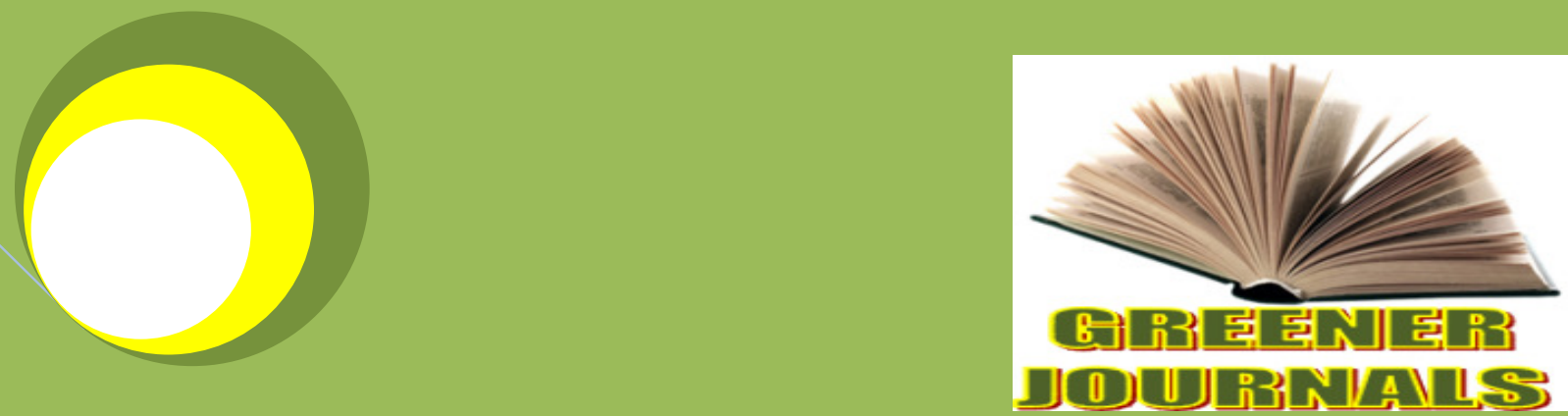

Greener Journal of Social Sciences GJSS ISSN: 2276-7800 Impact Factor 2012 (UJRI): 0.7863 ICV 2012: 5.99

\title{
Problems of \\ Conservation and \\ Preservation of \\ Library Resources in \\ African Academic \\ Libraries: A Review of \\ Literature
}

By

Ogunmodede Thomas A. Ebijuwa Adefunke Sarah 


\title{
Problems of Conservation and Preservation of Library Resources in African Academic Libraries: A Review of Literature
}

\author{
*Ogunmodede, Thomas A., Ebijuwa, Adefunke Sarah \\ Olusegun Oke Library, Ladoke Akintola University of Technology, P. M. B. 4000, Ogbomoso, Oyo State, Nigeria. \\ tamodede@yahoo.com, funkies_2005@yahoo.com \\ *Corresponding Author's Email: tamodede@yahoo.com
}

\begin{abstract}
This study investigated various problems of conservation and preservation of library resources in African academic libraries. Particularly, it examined the overview of preservation and conservation of library resources. It also studied the causes of deterioration of library information resources, among which are: natural aging process, level of use of library materials, inherent chemical content used in the process of paper making, high temperature and fluctuating relative humidity, improper handling of library materials among many others were equally discussed. Various preventive measures were equally discussed. Different challenges facing preservation and conservation of library resources in African Academic Libraries were presented. Useful suggestions were also made to ameliorate the situation.
\end{abstract}

Keywords: Library Resources, Academic Library, Preservation, Conservation.

\section{INTRODUCTION}

Conservation and preservation of deteriorating information resources in libraries has become a global phenomenon to which libraries must aggressively respond if their mission of providing information needs of their patrons would be met (Akande, 2009). Libraries acquire material to meet the informational or recreational needs of its clientele. When the material in one's care is allowed to deteriorate unchecked or become damaged in anyway, it may be difficult and may be ultimately difficult or the information it embodies available for use. It is the responsibility of the library staff to keep these materials in good physical condition so that they are available for users at all times. Materials in many libraries and archives throughout the country are still housed in conditions that leave much to be desired (Olatokun, 2008). A large portion of information recorded on audio or videotape about important events, people, etc., has been routinely wiped out in our electronic media houses (Popoola, 2003). This is a sad situation and one that is found in many libraries of African higher institutions. The deterioration of information-bearing material has a long history. Unless something is done to stop the process, library collections deteriorate and will continue to deteriorate. This is a battle that has to be waged against to prevent the deterioration of our intellectual heritage. Preservation is the action taken to anticipate, prevent, stop, or slow deterioration. It can also be described as the art of anticipating and preventing decay (Baker, 1981). Conservation is an act of preservation, protecting and shielding material from destructive influences that shorten their life span. The library plays a crucial role of protecting and preserving information-bearing materials from distortion, deterioration, and eventual loss because the materials are imperative. Academic libraries acquire information resources to meet the needs of their community. People use the collections as a result of increasing enrolments in higher education. There are shortages and decline in book budgets arising from the poor funding of the institutions as well as the high cost of books and other information resources. As a result, the libraries are left with damaged books, distorted tapes, scratched CDs, etc (Popoola, 2003).

The term 'Conservation' has been defined in the IFLA Principles for the Care and Handling of Library materials (2010) as "specific practices taken to slow down deterioration and prolong the life span of an object by direct intervening in its physical or chemical make-up. The composition of some of the media of storing information makes deterioration inevitable. Deterioration may set in through the natural ageing process or as a result of other factors such as chemical composition of the media of information, biological agents, environmental factors, physical agents and improper handling. There is, therefore, the need to take certain conservation measure to slow down deterioration to avoid losing these library resources. Conservation involves taking protective measures to prevent decay and consequently, the loss of library resources. It also includes taking preventive measures against agents of deterioration of books and other library resources. 
Preservation has been defined in the same IFLA Principles for the Care and Handling of Library Material to include "all the managerial and financial considerations including storage and accommodation provisions, staffing levels, policies, techniques, and methods involved in preserving library and archival material and the information contained in them.". While conservation is direct physical intervention arresting or slowing down deterioration of library materials, preservation involves both the direct and indirect action. In preservation consideration is given to every element that promotes the protection of the materials including the housing, storage system and security against such threats as theft, mutilation and poor handling. Preservation is, therefore, a more embracing concept and it includes conservation.

\section{Overview of Preservation and Conservation of Library Information Resources}

The library has the primary role of acquiring, processing, organizing, preserving as well as conserving the printed and non-printed information resources or materials for the use of their clientele. Library information resources refer to all those media for storing information such as textbooks, journals, newspapers and magazines, patents and standards, handbooks and manuals, directories, gazetteers, encyclopedias, atlases and maps, calendars and diaries, vertical files, theses and dissertations, tapes, videos, films, optical discs, cassettes, magnetic tapes, microforms, etc. Similarly, library information resources can simply be defined as book materials, microforms and electronic information materials capable of meeting information needs of the users (Popoola, 2003).

Popoola (2003) further submitted that until 1980's, preservation and conservation of library information materials was thought to be relevant to rare book materials by librarians and curators of collection of special materials. But, library information materials are bound to deteriorate or breakdown with time through the aging process, and to replace them may be difficult and expensive if not practically impossible. The modern day libraries and information centers are faced with the problem of deterioration of information materials in their holdings. Their information materials have deteriorated to the extent of losing their intellectual contents. It must be noted that thousands of volumes of information materials in most African academic libraries and information centres are either in state of brittleness or disrepair because of preservation problem.

According to the National Library of Australia (2004), one of the major crises facing libraries throughout the world is the rate of deterioration of their collections. Since library materials are composed primarily of organic materials, they are subject to natural deterioration. Most libraries' collections today are based on paper - either in book or sheet form - bound volumes, newspapers, serials, manuscripts, maps, watercolours, prints and drawings. Some libraries have an important collection of oil paintings, a small collection of objects, and a large collection of photographic materials including negatives, prints, glass negatives and photographic albums. The collections of modern materials such as sound tapes and electronically stored information such as CD ROMs and computer discs is growing rapidly, and most libraries' collections are essentially impermanent (National Library of Australia, 2004). Unlike museum items that are rarely handled, library materials are meant to be used. They are vital sources of information which cannot be conserved and stored away in an ideal and secure environment to arrest their decay. This is the dilemma of library preservation - to make information accessible, while still ensuring its ultimate survival. As the IFLA-PAC China Centre (2006) puts it: the core activity on preservation and conservation is to ensure that significant library and archive materials, published and unpublished, in all formats, will be preserved in accessible form for as long as possible.

\section{Causes of Deterioration}

Men are unquestionably the greatest enemies of the materials on which they record their thoughts. To the long list of great libraries vandalized by conquering armies or burned in hate, must be added the incalculable loss and damage caused by petty theft, malicious mischief and careless handling by individuals.

Improper and faulty actions taken by the library staff may cause deterioration to library materials. Cheap and improper materials are often used for mending and repairing. Wrong insecticides are used for fumigation, repairing, restoration and lamination work, which are usually done by untrained personnel. And all these conditions cause deterioration or worse, aggravate deterioration of library materials (Mahapatra andWamukoya, 2004).

Edhebe (2004) stated that much avoidable damage is done to books by well- meaning but uniformed librarians through the following:

1. Use of pressure sensitive tapes.

$2 . \quad$ Indeterminate use of polyvinyl acetate and other synthetic adhesives.

3. Use of highly acid paper for protective wrappers.

4. Use of wood backing in print, picture and map frames.

5. Amateur lamination.

6. Improper storage. 
Pressure sensitive tapes are perfectly satisfactory for sealing packages, but should never be used for repairs on anything but the most inexpensive books. At best, these repairs are only temporary and the chemicals in some adhesives soon discolour the paper with a stain that is impossible to remove. Some tapes now available claim to be non-staining and more permanent but since there is little information available on the materials in these tapes, it would be unwise to use them on anything other than books and papers that are expected to be discarded after a reasonable period of use.

Mahapatra and Chakrabarti (2003) reported that extravagant claims have been declared by some manufacturers of polyvinyl acetate regarding the alleged capabilities of these materials to transform old books like new. These white emulsions generously painted on workout books, are claimed to fasten separated covers, consolidate rotted leather and rejuvenate cloth. A very good numbers of fine volumes have been ruined by the improper use of these products. It must be noted that polyvinyl acetate emulsions are good adhesives and nothing more. When used as one would use paste or glue, they make very strong bonds which can rarely be separated without damaging the fastened materials. Since one of the basic principles of rare book and archive restoration is that nothing shall be done in the restoration that cannot be undone if necessary, these irreversible adhesives should be avoided for all except general library work.

According to Mahapatra and Chatevabarti (2003), the following physical and chemical situations are responsible for deterioration of documents, either by one or more.

1. Natural aging of paper since the major constituents are of organic nature. Such inevitable deterioration can be minimized to a large extent by proper housekeeping.

2. In the manufacturing of paper sometimes fibres are used with low cellulose content or sometimes noncellulose materials of the lignin type are used by which paper becomes degenerated very easily.

3. Mineral and chemical compounds used as basic constituents of paper affect the durability of paper.

4. Impurities in the ingredients used as basic constituents of paper cause inevitable deterioration.

5. Presence of acidic sizing materials such as, alum, rosin, etc, causes the acidic effect.

6. Oxidizing agents present in the constituents of paper make the paper weak, discoloured and disintegrated. Presence of metal accelerates oxidation.

7. Alkalis used in the manufacture of paper affect it if used in a higher quality. Fungi grow very easily on such paper.

8. Heat and exposure to light make the paper brittle and fade in colour.

9. Dust particles make the paper discoloured, invite chemical impurities and accelerate biological growth.

10. Acidic impurities present in the atmosphere make the paper discoloured and degenerated.

11. Sulphyric acid is formed from Sulphur dioxide present in the air.

12. Moisture and humidity by which not only the tissues of paper are disintegrated but also conditions are created for biological attack.

13. Films are very sensitive to excessive heat, dryness, humidity and moisture.

14. Chemicals present in audio-visual materials can cause deterioration under adverse environmental condition.

15. Because of the basic elements used in the audio or video tape, deterioration is caused for physical and chemical change within the materials under adverse environmental condition.

Thus, the causes of deterioration of library materials may be grouped under three broad categories: natural aging, intrinsic or inherent factors and external condition. Natural aging indicates the durability of a particular type of library material as physical entity such as various types of paper book binding materials, films, audio-tapes, etc. The ingredients used in the particular material are of good quality, the processes of manufacturing are properly done and no substance is used for any purpose which may cause deterioration in future under any condition, the material will be durable and long-lasting and it can endure adverse conditions. In such case natural aging with take more time. If the basic elements are of poor quality, substances used which may cause deterioration, manufacturing process are not properly performed, the material will be less durably and natural decay or aging will be faster, of course, to the extent the material has been manufactured having basic ingredients. It is inevitable that each material is subject to natural decay.

Intrinsic or inherent factors refer to the basic ingredients used in the manufacture of physical entity of library materials and the manufacturing process. In case of paper these basic ingredients are low quality material for paper pulp, chemicals used for processing of pulp, sizing and loading substances and processes involved in the paper manufacture.

The ingredients of paper used for reading materials which constitute the major bulk of library collection, are of organic nature and for this reason are prone to decay and deterioration naturally by passage of time. This situation is accelerated by other constituents of book such as board, cloth, binding materials, ink, colour adhesive, etc. The causes of deterioration can be grouped under two categories_ physical deterioration and chemical deterioration. Adverse environmental conditions accelerate both types of deterioration and thus, become the root cause of deterioration. 


\section{Preventive Measures}

Preservation methods are adopted based on location, weather, and environment. These conditions can be attained using an appropriate environment and the various other methods like chemical treatment, fumigation, restoring faded links, bleaching, etc.

\section{Environmental Conditions}

Much research has been done on finding out the ideal condition of humidity and temperature for the storage of books, and archival materials. Gallo, an Italian chemist suggested that the ideal humidity between $40 \%$ and $65 \%$ , and the temperature between $18^{\circ} \mathrm{C}$ and $20^{\circ} \mathrm{C}$ are good for conservation of books.

It is very difficult to control atmospheric conditions, which are constantly fluctuating. The control of temperature and humidity inside the room implies their constant measurement. A number of sensitive instruments are available for measuring temperature and humidity. Some instruments are of the recording type and make it possible to record temperature and humidity, or both over a length of time. Too much of relative humidity or too little of it is equally dangerous. The recording instruments help us to know the actual condition of humidity. It is necessary to find out the humidity and to maintain the right humidity. During the summer, relative humidity falls below $50 \%$ and the atmosphere becomes dry. It is necessary to increase the content of moisture in the air. Arizona (2010); Sunil and Kumar (2009); Mahapatra and Chalkrabarti (2003); and Olatokun (2008) suggested the use of air condition in storage area. The use of thermometer and barometer are necessary to check temperature and relative humidity level in the storage area.

Fire may be prevented by banning smoking in the library. Inflammable articles like kerosene, petrol, waste paper should be kept outside. Electric wiring must be enclosed in metal conducts to localize the effect of sparks due to short circuits. Control switches for lighting should be fixed outside the room and the mains switches should be off when the stack area is closed. A good method of limiting the fire is to partition the stack area into different portions with metal partitions which have metal doors and to isolate them from one another through shutting the doors in case of fire outbreak. This will check the spreading of fire and will help in its control. Sufficient number of fire extinguishers should be kept at strategic points in the library (Sunil and Kumar, 2009).

\section{Human Beings}

Readers, with a stealing inclination, can be checked through preventive measures like spying and installing thiefcatching devices. The fundamental factor in minimizing unnecessary damage to the library material also depends on the careful handling of the materials on the part of both staff and reader. Videotapes or slides regarding the handling of books should be shown to the new employees and the readers. Books should never be pulled off the shelves by head caps. When more than four to five books have to be carried within the library, care should be taken to reduce the possibility of dropping off the books. Over- sized books should be handled with particular care. Books should not be jammed on to overcrowded shelves that may cause damage to binding (kneale, 2000; Ovowoh and Iwhiwhu, 2010).

\section{Chemical Methods of Preservation}

Some standards should be followed while using chemicals for preservation. Examination of the object thoroughly and the isolation of deterioration factors must be the starting point. Only standard materials must be used. The methods and materials used should not damage the original condition of documents. All commercial products whose composition is unknown must not be used. It is better to use pure reagents. Caution is to be employed in deciding on restoration or cleaning. For restoration of materials the least drastic method should always be tried initially.

\section{Preservation from Insects and Pests}

Mahapatra and Chalkrabarti (2003) noted that insects and pests can be controlled by chemical treatments like fumigation and using chemicals in the affected areas. The optimal range of temperature for microorganisms to survive is $20^{\circ} \mathrm{C}$ to $40^{\circ} \mathrm{C}$ and for insects is $20^{\circ} \mathrm{C}$ to $30^{\circ} \mathrm{C}$. Termite's infection starts from the soil. To control termites, creation of chemical barrier around the building using crude cresosote in kerosene (1:1) or Siedren in water (1:60) is recommended. Dieldrins, insecticides like DOT are being used in some libraries to control a variety of insects. DDT acts as a stomach poison to insects and affects their sensory organs and nervous system and causing violent agitation followed by paralytic death, this can be achieved through the process of fumigation. 


\section{Restoring Faded Inks}

Iron gal inks fade in adverse conditions because tannin in the ink decomposes and disappears. The paper containing the faded writing may be treated for few seconds with a dilute solution of ammonium hydro sulphide until the writing darkens. The faded writing may also be treated with $3 \%$ solution of tannic acid so as to darken the iron oxide and bring back the writing.

\section{Bleaching}

The removal of general discoloration is necessary, very often to give the document freshness. A bleaching agent, which is less injurious to the fibres of the document material, is chloramines. It is invariably used as $2 \%$ solution in water.

\section{Lamination}

It is the process in which a document is embedded between sheets of synthetic plastic film or tissue. The synthetic plastic is the adhesive and the tissue paper is the reinforcement. The adhesion of the synthetic plastic may be brought about by using pressure and heat or by using suitable solvent. The temperature required is about $140^{\circ} \mathrm{C}$ to $150^{\circ} \mathrm{C}$ for 22 to $36 \mathrm{~kg} / \mathrm{cm}^{2}$. At this temperature and pressure, the synthetic plastic cellulose accurately melts and seals up firmly. This makes good reinforcement.

\section{Repair}

A document may suffer a minor physical change such as tears, wrinkling, scattered holes, and gross deterioration such as abnormally large number of holes and tunnels caused by insects. Latter case calls for the strengthening of the sheets with chiffon and through the modern process of lamination.

\section{Racking and Shelving}

The racks, shelves and containers also conform to the exigencies of good storage that is resistant to dirt, dampness, fire, and microorganisms. Proper choice of material and design of racks, shelves and containers avert the dangers to the documents. Racks should be made of steel. They may be arranged width wise along the length of the rooms. Steel racks may be suitably painted to avoid rusting. Flat dishes of metal should be placed under the legs of the racks and filled with water or insecticides solution to prevent insects from going up the racks from the floor. The shelf should be made of battens so that the airflow is maintained underneath the archival material kept on them. For long rolled documents, Jenkinson in Mahapatra and Chalkrabarti (2003) suggested cantilever brackets built into the wall and provided with teak battens. These racks may be placed close together one above another, each taking one layer of rolled maps, etc., of any length up to 5 . Jenkinson suggested that cleaning space must be provided on every floor keeping the document while the place is being cleaned (Mahapatra and Chalkrabarti, 2003; Sunil and Kumar, 2009).

\section{Dust Removal}

Dust accumulates quickly in our climate, so it is necessary to remove it regularly. Dusting cannot be done properly with cloth and broom, because particles of dust rise into air and again settles down in some other part of the room or in other shelves. To overcome these problem libraries should use vacuum cleaners. Vacuum cleaners also helps in saving a lot of time otherwise spent on brooming and cleaning.

\section{Problems of Preservation and Conservation of Information Materials in Africa}

A survey of literature on preservation and conservation of library materials in Africa as stated by Popoola (2003) and Olatokun (2010) revealed that the prominent inhibitors to effective and efficient preservation of information materials in African libraries, archives and record centres include the following:

(i) Inadequate Finance: Almost all African libraries, archives and information centers do not allocate adequate funds in their annual budget for the preservation and conservation of information materials in their holdings. This has really caused the low priority or lack of desired attention given to the preservation and conservation of information resources by the management of such libraries and archives.

(ii) Inadequacy of Equipments/Materials: Lack of suitable or inadequate equipments and materials contributes significantly to the present poor status of preservation and conservation of information materials in African libraries, archives and information centers. Some of the essential materials and 
equipment required for setting up functional conservation and restoration laboratories in African libraries and archives are not available locally (ESARBICA, 2002).

(iii) Unfavourable Government Economic Policies: The economic policies of most African governments do not favour library and archival services, so preservation and conservation activities are not given the priority attention they deserve. Such economic policies include those concerning high duties and tariffs charged on imports of preservation and conservation equipments.

(iv) Tropical climate: The effects of tropical climate of excessive temperature, high relative humidity, dust, and rodents that feed on paper-based materials cause rapid deterioration and decay of information resources in African Academic Libraries and archives. These agents of rapid deterioration and decay of information materials add more to the costs associated with conservation and restoration of information materials in African libraries archives and records offices (UNESCO, 2000). Mwiyeriwa (1998) while stressing the great need for a well-established document repair and conservation units in Africa observes that with the exception of air, fungi, insect, and pest are more pronounced in the continent than elsewhere.

(v) Manpower and other infrastructure: For any preservation and conservation programme to succeed in libraries and archives there must be adequate and well-trained manpower (Ngulube, 2002). This is because preservation and conservation of information resources is a specialized field of knowledge that requires information professionals who understand the physical and chemical nature of the materials in their library and archive holdings. Popoola (2003) advocates the need to expose librarians and archivists to conservation and restoration practices during their training. Akussah (1991) suggests that such a training programme should include, operating environmental control, storage and housing, operating environmental systems, designing new buildings or renovation of buildings. Africa has not been able to train students adequately in the area of conservation and restoration of information resources due to lack of functional laboratories where students could undergo practical works. Added to this is the problem of inappropriate buildings, poor power supply and water supply that pose great threat to preservation and conservation of information resources in African countries (Kemoni and Wamukoya, 2000). Kemoni and Wamukoya (2000) also identified lack of information (IT) skills due to inadequate training as one of the impediments to the management of electronic records at Moi University in Kenya.

(vi) Lack of Preservation and Conservation Policy: Most African countries do not have a national information policy which makes the formulation of preservation and conservation policies in the libraries and information centers out of the question (Wamukoya and Mutula, 2005). Kemoni (1996) reviewed the conservation programmes of archive materials in Kenya and found that the conservation departments did not have a disaster control plan. The absence of such a plan means that in the event of a disaster, they would not be in a position to respond to the disaster with the urgency that is required.

(vii) Quality of paper and ink: The low quality of paper and ink used in the production of information materials especially library book materials and paper-based records in archives and records offices pose serious danger to preservation and conservation of information materials in African countries (Popoola, 2003; Mahapatra and Chakrabarti, 2003).

(viii) Maintenance culture: African countries generally lack maintenance culture. The managements of libraries and archives in Africa have poor maintenance culture of infrastructural facilities such as telephones, electricity, water supply, laboratory equipment, buildings, disaster control devices, etc meant for their preservation and conservation operations. In fact, this factor is responsible for the quick deterioration of their collections. Preventive preservation of information resources calls for constant cleaning of the library/archive building as well as information materials therein. Restoration techniques such as binding and lamination of paper-based information may be used to reduce conservation cost (Popoola, 2003).

(ix) Administrative problem: Majority of the library and archive managers concentrate much on the effective provision of information services to users. There is a lack of proper recognition of the need for preservation, conservation and restoration of information resources. They have failed to realize that preservation and conservation staff for improved job performance by providing good conditions of service (Popoola, 2003; Olatokun, 2008).

(x) Cooperative preservation and conservation venture: African countries lack cooperative preservation and conservation venture either at the regional or local level. With limited resources and diminishing budgets, African libraries and archives can undertake cooperative ventures which may involve the setting up of a joint conservation and restoration laboratory or microfilming unit. Such a venture can deal with the repair of information materials and training of conservation and restoration staff. Allied institutions like libraries or archives can pool resources together at regional or local level to establish a national preservation and conservation centre well stocked with modern equipment and materials, qualified manpower and adequate finance for the repair of damaged information resources. Kemoni (1996) supports this view; he submits that the need to set up a national preservation office in Kenya to coordinate all preservation and conservation issues cannot be underscored. He stresses that the broad objectives of such an office will include: 
a) Creating and promoting awareness on the need to preserve and conserve archival materials.

b) Organizing seminars, workshops and conferences to discuss issues related to conservation of archive materials.

c) Acting as a centre for information dissemination.

d) Soliciting for funds nationally and internationally to purchase equipment and materials.

e) Bearing responsibility for the publication of a journal where archivist can exchange ideas through their individual contributions on issues related to the preservation of archival materials.

Public enlightenment campaign: Lack of public enlightenment campaign has been the bane of poor preservation and conservation of information resources in African academic libraries. Information professionals often times criticize the government of their countries in Africa for not giving sufficient consideration to preservation and conservation of the national heritage. It must be noted that the information managers must embark on public enlightenment campaigns on the need to preserve and conserve national heritage in their countries. For proper conservation of library and archival materials in Africa, the consciousness of the general public and of the authorities concerned must be raised on the need for the government to prioritize preservation and conservation of the recorded knowledge.

\section{CONCLUSION}

The study was designed to investigate the preservation and conservation problems of library materials in African academic libraries. The literature reviewed gives an informative account that there is no written policy on preservation and conservation in academic libraries. It is impossible to cultivate the culture of preservation and conservation in such libraries, which places information-bearing materials at a high risk for extinction.

The main constraints to proper preservation and conservation in academic libraries are lack of funds, lack of qualified conservation librarians, non-committal attitude of staff, and lack of adequate and dependable storage facilities. Very few librarians are conversant with preservation management, thus militating against any comprehensive preservation programme. There is need to improve library materials in libraries; orientation for staff, everyday care, and staff trained on preservation and conservation, government positive attitudes towards preservation and conservation among many others are necessary.

\section{RECOMMENDATIONS}

The following recommendations are made:

- $\quad$ A good policy on short-term to long-term preservation and conservation should be formulated.

- $\quad$ Professionally trained conservators should be recruited, and training and retraining of staff should be encouraged.

- $\quad$ There should be an annual budget allocation for preservation and conservation.

- $\quad$ All libraries should adopt everyday care methods.

- $\quad$ A well-equipped bindery section with trained staff should be established.

- There should be regular orientation on the preservation and conservation of library materials.

\section{REFERENCES}

Akande SO (2009). Knowledge, perception and Attitudes of library personnel towards preservation of Information Resources in Nigerian Federal University Libraries. Library philosophy and Practice. Retrieved from http://www.vidaho.edu/mbolin.htm.on 21st January, 2011 (pdf.)

Akussah H (1991). The Preservation of Traditional Library and Archival Materials in the Harsh Ghanaian Environment. African Journal of Library, Archives and Information Science, 1 (1): 19-28.

Arizona (2010). Preservation Arizona State Library, Archives and Public Record, A division of Secretary of State.

Baker N (1981). Conservation and Preservation: A Problem of Library Management: A British view. Libri 31 (3): 197.

Edhebe C (2004). The Preservation and Conservation of Materials in the college of Education Library, Warri. Abraha: Delta State University.

ESARBICA (2002). Minutes of the ESARBICA Executive Board meeting held at the mountain inn. Mbabane, Swaziland 11-13 March, 2002.

IFLA-PAC China (2006) .Strategic plan 2006-2008. Retrieved 22nd December, 2010 from: http://www.nlc.gov./cn/en/service/iflapac chinacenter/strategem.htm. 
IFLA Principles for the Care and Handling of Library Materials (2010). International Preservation Issues, Number One. Downloaded On-line on $27^{\text {th }}$ April, 2010 from http://archive.ifla.org/Vl/news/pchlm.pdf.

Kemoni HN (1996). Preservation and Conservation of Archive Materials: The case of Kenya. African Journal of Library, Archives \& Information Science, 6 (1): 46-51.

Kemoni HN and Wamuhoya $\mathrm{J}(2000)$. Preparing for the management of electronic records at mo, University, Kenya. African Journal of Library, Archives and Information Science 10 (2): 125-138.

Kneale RA (2000). Reclaiming the JAC library: Preserving and Conserving Library Materials. Information Outbook, 4 (7).

Mahapatra PK and Chakrabarti B (2003). Preservation in Libraries: Perspectives, Principles and Practice New Delhi: ESS Publication.

Mnjama N and Wamukoya J (2004). E-government and e-records management. Paper Presented at the SADC Workshop on E-government, Gaborone, Botswana, 14-16 April 2004.

Mwiyeriwa S (1998). The Development of Archives in Africa: Problems and Prospects. In Wise, M. (ed.) Aspects of African Librarianship. London: Mansell.

National Library of Australia (2004). Preservation policy Retrieved December 17th, 2010: from: http://www.nla.gov.au/policy/pres.html.

Ngulube P (2002). Preservation reformatting strategies in selected sub-saharan African archival institutions. African Journal of Library, Archival and Information Science 12(2): 117-132.

Olatokun WM (2008). A survey of preservation and conservation practices and Techniques in Nigerian University Libraries. Library and Information Science Research Electronic Journal 18(2) Retrieved on December 17th, 2010 at http://libres.curtin.edu.aul. (pdf).

Ovowoh RO and Iwhiwhu BE (2010). Preserving Information Bearing Material in Higher Education Institutions in Nigeria. Library Philosophy and Practice. Retrieved 21st January, 2011 from. http//www.edu/ mbolin.htm.

Popoola SO (2003). Preservation and Conservation of Information Resources. University of Ibadan, Nigeria: Distance Leaving Centre.

Sunil A and Kumar P (2009). Preservation of Library Materials: Problems and Perspective. DESIDOC. Journal of Library and Information Technology. 29 (4): 37-40.

UNESCO (2000). Safeguarding our documentary heritage. Retrieved December 17, 2010 from http://webworld.unesco.org/.

Wamuhoya J and Mutula SM (2005). E-records Management and Governance in East and Southern Africa. Malausian Journal of Library and Information Science. 10(2): 67-83. 